https://doi.org/10.22319/rmcp.v12i4.5699

Revisión bibliográfica

\title{
Linfadenitis caseosa: factores de virulencia, patogénesis y vacunas. Revisión
}

Maria Carla Rodríguez Domínguez a

Roberto Montes de Oca Jiménez ${ }^{\mathrm{a}^{*}}$

Jorge Antonio Varela Guerreo ${ }^{\text {a }}$

${ }^{a}$ Universidad Autónoma del Estado de México. Centro de Investigación y Estudios Avanzados en Salud Animal (CIESA). Facultad de Medicina Veterinaria y Zootecnia. km 15.5 Carretera Panamericana Toluca-Atlacomulco, Toluca, Estado de México, México.

* Autor de correspondencia: romojimenez@yahoo.com

\section{Resumen:}

La linfadenitis caseosa es una enfermedad que afecta la producción ovina y caprina a nivel mundial. El agente etiológico es una bacteria Gram positiva, intracelular facultativa denominada Corynebacterium pseudotuberculosis biovar ovis. La enfermedad puede cursar con un desarrollo cutáneo o visceral, provocando deterioro en la condición física del animal, así como pérdidas en la producción de leche y carne, decomiso de las canales, rechazo de las pieles y como consecuencia, grandes pérdidas económicas. El estudio de los factores de virulencia y los mecanismos de patogénesis han permitido comprender esta enfermedad, así como establecer las moléculas diana para el desarrollo de nuevas vacunas. Existen vacunas comerciales disponibles a nivel mundial; sin embargo, la protección conferida por éstas no ha sido eficaz en el control de la enfermedad. Actualmente el uso de nuevas tecnologías ha permitido la obtención y caracterización de proteínas con potencial inmunogénico para el desarrollado de nuevas vacunas, las cuales podrían ser una alternativa para incrementar la protección. En el presente trabajo se exponen los principales factores de virulencia de Corynebacterium pseudotuberculosis, sus implicaciones en la patogénesis y las tendencias actuales en las formulaciones vacunales. 
Palabras clave: Linfadenitis caseosa, Corynebacterium pseudotuberculosis, Factores de virulencia, Patogénesis, Vacunas.

Recibido: 01/06/2020

Aceptado: 08/01/2021

\section{Introducción}

La linfadenitis caseosa (LAC) es una de las enfermedades que más afecta las producciones ovinas y caprinas a nivel mundial ${ }^{(1)}$. El agente etiológico de la enfermedad, Corynebacterium pseudotuberculosis biovar ovis, causa una infección crónica que se caracteriza por la formación de abscesos en nódulos linfáticos cutáneos o viscerales. Esta enfermedad provoca el deterioro en las condiciones físicas de los animales, disminución de la producción de lana ${ }^{(2)}$ carne $^{(3)}$ y leche ${ }^{(4)}$, así como desórdenes reproductivos ${ }^{(5)}$. En Australia el análisis de tres granjas de la región Occidental, para un total de 600 animales evaluados, permitió establecer que la infección por $C$. pseudotuberculosis produjo la disminución en la producción de lana grasa en 3.8-4.8 \% y de lana limpia en 4.1-6.6 \%. Basados en los datos obtenidos la pérdida anual en la producción de lana estaría alrededor de los $\$ 17$ millones de dólares australianos (AUD) ${ }^{(2)}$. Las pérdidas en la producción de carne se han estimado entre los \$12-13 millones de $\mathrm{AUD}^{(6)}$. Otros estudios indican que las pérdidas en general serían de alrededor de $\$ 30$ a 40 millones de dólares, contemplando el rechazo de carne y canales ${ }^{(7)}$. En Canadá se identificó que entre un 3 a $5 \%$ de la carne y 0.02 a $0.03 \%$ de los animales, son rechazados durante procesos de inspección de las plantas productoras ${ }^{(8)}$. Estos hechos tienen un impacto negativo en las exportaciones, disminuyendo las posibilidades de comercialización $^{(9)}$.

Corynebacterium pseudotuberculosis es un microorganismo zoonótico, por lo que también afecta al hombre, siendo más vulnerable el personal que trabaja en la producción de pequeños rumiantes $^{(10)}$. La LAC ha sido reportada en diversos países como China ${ }^{(11)}$, Australia ${ }^{(12)}$, Brasil $^{(13)}$, Canadá(14), Estados Unido ${ }^{(8)}$ y México $^{(15,16)}$. La propagación de la enfermedad pudo ser originada por ovejas enfermas exportadas desde España a Sur América y desde Australia a Norte América y al Medio Oriente ${ }^{(17)}$. La enfermedad es escasamente notificada, según los resultados de una encuesta realizada a 264 veterinarios y 510 agricultores en el Reino Unido. Solo el $18 \%$ de los veterinarios había visto al menos un caso de la enfermedad y el $45 \%$ de los granjeros habían notado la formación de abscesos en sus ovejas. Pocos productores investigan la causa de los abscesos, pero de 32 granjas que fueron estudiadas mediante diagnóstico de laboratorio, 24 fueron confirmadas con la presencia de la enfermedad ${ }^{(18)}$. La frecuencia de presentación de la LAC en cada región o país depende principalmente del tipo 
de explotación, manejo y programas de control. Los rebaños en producciones extensivas, el pastoreo y la actividad de esquila condicionan la aparición de la enfermedad ${ }^{(19)}$. El tratamiento con antibióticos, las intervenciones quirúrgicas y la aplicación de soluciones desinfectantes en los abscesos externos ${ }^{(20,21)}$, no siempre constituyen opciones eficaces. El contenido purulento de los abscesos puede contaminar el suelo, alimento y equipos de manejo $^{(22,23)}$ y aunque $C$. pseudotuberculosis in vitro exhibe sensibilidad a un amplio rango de antibióticos ${ }^{(24)}$, in vivo el tratamiento es difícil debido a la naturaleza intracelular de la bacteria $^{(25)}$ y al contenido grueso, seco y fibroso del absceso ${ }^{(8,9)}$. La Organización Mundial de Sanidad Animal (OIE), contempla a la LAC dentro de la lista de enfermedades que requieren el desarrollo de vacunas eficaces para reducir el uso indiscriminado de antimicrobianos ${ }^{(26)}$. Existen vacunas comerciales a nivel mundial contra LAC; sin embargo, la protección conferida por éstas no ha sido eficiente en el control de la enfermedad ${ }^{(11)}$. Actualmente, el uso de tecnologías de nueva generación ha permitido el desarrollado de nuevas vacunas experimentales, las cuales podrían ser una alternativa para mejorar la protección. Las nuevas formulaciones buscan incluir moléculas, principales factores de virulencia, que permitan la activación del sistema inmune humoral y celular ${ }^{(27)}$. La presente revisión de la literatura aborda las temáticas referentes a los principales factores de virulencia, su relación en la patogénesis y las estrategias empleadas para el desarrollo de nuevas formulaciones vacunales contra linfadenitis caseosa.

\section{Características generales: Corynebacterium pseudotuberculosis}

El género Corynebacterium incluye numerosas especies de gran importancia para la industria médica, biotecnológica y veterinaria. La base de datos PATRIC Database, en el 2017 contaba con el reporte de 466 genomas y 83 especies de Corynebacterias ${ }^{(28)}$. Corynebacterium pseudotuberculosis pertenece a la familia Corynebacteriaceae, género Corynebacterium. Presenta una morfología cocobacilar con amplitud de 0.5 a $0.6 \mu \mathrm{m}$ y 1.0 a $3.0 \mu \mathrm{m}$ de longitud. Este microorganismo es un patógeno intracelular facultativo, no flagelado, no formador de esporas ni capsula. Tiene la capacidad de crecer en anaerobiosis, degrada la galactosa, maltosa, L-y D-arabinosa y glucosa sin producción de gases. En medio de cultivo caldo simple, el crecimiento es escaso sin turbidez; sin embargo, en caldo de Infusión CerebroCorazón, BHI (por sus siglas en inglés, Brain Heart Infusion) se obtiene un crecimiento abundante con sedimento de color blanco amarillento ${ }^{(1)}$. La pared celular de la bacteria está formada por una capa de peptidoglicano compuesto por ácido meso-diaminopimelico (mesoDAP), arabinosa y galactosa como azucares principales. En las reacciones de la vía de biosíntesis II de peptidoglicano; el ácido meso-DAP es el producto de la reacción catalizada por UDP-N-acetilmuramil-tripéptido sintetasa, enzima que ha sido identificada en cepas de Corynebacterium $^{(29)}$. El peptidoglicano a su vez está unido covalentemente con arabinogalactanos que forman un enrejado, que se encuentra unido a una capa externa de ácidos corynomicólicos (22 a 36 átomos de carbono), que se unen a trehalosa, siendo el 
extremo de la pared más expuestos con el exterior ${ }^{(30)}$. Esta estructura lipídica actúa como una barrera, con permeabilidad selectiva mediada por proteínas integrales de membranas llamadas porinas $^{(31)}$. La exotoxina Fosfolipasa D (PLD) es considerada el principal factor de virulencia y puede ser detectada mediante un ensayo de hemólisis sinérgica frente a Rhodococcus equi o por inhibición de la ß hemolisina del Staphylococcus aureus. Las cepas de C. pseudotuberculosis son clasificadas en biovar equi para los aislamientos que presentan actividad enzimática nitrato reductasa (nitrato-positivo) y biovar ovis para aquellas cepas que no presentan dicha capacidad (nitrato-negativo) ${ }^{(1)}$. El biovar ovis es el agente causal de la enfermedad LAC y ha sido aislado de ovejas ${ }^{(15)}$, $\operatorname{cabras}^{(16)}$, antílopes ${ }^{(32)}$, $\operatorname{vacas}^{(33)}$, alpacas ${ }^{(34)}$, llamas $^{(35)}$, cabra montés ${ }^{(36)}$ y $\operatorname{cerdos}^{(37)}$.

El biovar equi provoca la formación de abscesos en tejido muscular del área pectoral de equinos y en menor medida lesiones internas ${ }^{(38)}$, así como también se ha aislado de camellos $^{(39)}$ y búfalos ${ }^{(40)}$. C. pseudotuberculosis provoca infección en humanos, con la existencia de casos reportados principalmente en países dedicados a la ganadería de pequeños rumiantes. Los síntomas clínicos incluyen adenopatías axilares, inguinales o cervicales, fiebre y mialgias, con evolución crónica o subaguda, en algunos casos también puede generar neumonía $^{(10)}$.

\section{Factores de virulencia}

Los factores de virulencia son las estructuras y moléculas que le confieren la capacidad a la bacteria de ser patógena. La adquisición de genes por transferencia horizontal ha sido trascendental en la evolución de la patogenicidad de las bacterias; ya que las funciones de los genes adquiridos le han permitido adaptarse a las distintas condiciones ambientales, incluyendo la supervivencia en diferentes nichos durante la infección a los hospederos. La mayoría de los genes de virulencia de $C$. pseudotuberculosis están agrupados en el genoma en regiones denominadas islas de patogenicidad (PAI). En C. pseudotuberculosis 16 PAI se han identificado, denominadas PiCp, donde la presencia de un gen de transposasa en la PiCp1, posiblemente permitió la incorporación de las PAI en el genoma ${ }^{(29,41)}$. Estas regiones contienen varios genes implicados en la adhesión, invasión, colonización, propagación dentro del hospedero, supervivencia en el interior de las células infectadas y la evasión del sistema inmune. Las secuencias de las PiCp tienen un alto nivel de similitud (82-100\%) intra-biovar en las cepas ovis, las cuales presentan de 78 a $91 \%$ de similitud con respecto al biovar equi. Sin embargo, las cepas de biovar equi contienen grandes deleciones y un menor nivel de similitud intra-biovar (77-88 \%) y también en comparación con las PiCp de biovar ovis $(62-74 \%)^{(41)}$. 


\section{Ácidos corynomicólicos}

Los ácidos corynomicólicos, se encuentran formando parte de la capa externa de la pared celular de la bacteria, la cual constituye una barrera protectora y permeable. La unión de estos a moléculas de trehalosa, conlleva a la formación de estructuras curvas, que bloquea el acceso de moléculas (antibióticos o lisosimas) hacia el peptidoglicano, confiriendo protección mecánica ${ }^{(30,31)}$. A diferencia de los ácidos grasos lineales de los fosfolípidos, los ácidos corynomicólicos son ácidos grasos hidroxi- $\beta$-ramificados, que requieren carboxilación y condensación de dos ácidos grasos para su síntesis. Las enzimas AccD2 y AccD3 son carboxilasas ampliamente conservadas en la familia Corynebacteriaceae, involucradas en la generación de intermediarios para la síntesis de los ácidos corynomicólicos. Otras enzimas que participan en la síntesis son la AccD1 para la elongación de la cadena de ácidos micólicos y la FadD una AMP ligasa ${ }^{(29)}$. La inoculación de ácidos corynomicólicos en ovinos demostró que la haptoglobina (Hp) aumentó tres veces su concentración, así como también dos veces los niveles de amiloide sérico A (SAA), proteínas indicadoras de inflamación e infecciones agudas $^{(42)}$. Estos resultados indican su potencial virulento, ya que por sí solos, son capaces de inducir en el hospedero reacciones de inflamación, que contribuye a la formación de granulomas.

\section{Fosfolipasa D, PLD}

La exotoxina Fosfolipasa D es considerada el factor de virulencia principal de $C$. pseudotuberculosis. El gen pld fue identificado y secuenciado en 1990, forma parte de la isla de patogenicidad PiCp1 y codifica para una proteína de $31.4 \mathrm{KDa}^{(43)}$. La comparación de la secuencia de la proteína PLD de $C$. pseudotuberculosis reveló que presenta mayor similitud con Fosfolipasa A2; sin embargo, PLD no pertenece a la familia de las fosfolipasas debido a que carece del motivo HKD conservado en esta familia ${ }^{(43)}$. La PLD es clasificada como una Esfingomielinasa D (SMasaD; EC 3.1.4.41), también conocidas como esfingomielina fosfodieasterasas D o fosfolipasa D (PLD), que cataliza la escisión hidrolítica de la esfingomielina para producir colina y ceramida 1-fosfato o colina y ácido lisofosfatídico $(\text { LPA })^{(44)}$. Los compuestos derivados de la degradación de la esfingomielina causan la agregación plaquetaria, hiper-permeabilidad endotelial y respuestas pro-inflamatorias ${ }^{(45)}$. La acción enzimática de PLD hidroliza la esfingomielina, componente principal de las membranas celulares, lo que conlleva a una alteración de la morfología de la membrana diana. La PLD contribuye a la diseminación y persistencia de la bacteria en el interior de los macrófagos ${ }^{(46)}$. El gen pld presenta una secuencia ampliamente conservada en las cepas de C. pseudotuberculosis, y cuando ésta se encuentra modificada, se dificulta la capacidad de producir la enfermedad ${ }^{(41)}$. 


\section{Endoglicosidasa, CP40}

La proteína CP40 es codificada por un gen con un marco abierto de lectura de 1,137 pb, que se encuentra ubicado corriente abajo del gen pld en la PiCp1. Fue descrita como enzima con actividad proteasa serina ${ }^{(47)}$, pero en otro estudio, el análisis de la secuencia permitió su agrupación más cercana junto a endoglicosidasas y más lejos de las secuencias de proteasas de serina ${ }^{(48)}$. En este trabajo se propuso que su actividad enzimática es de endoglicosidasa, mediadora de la hidrólisis de enlaces glicosídicos, proteínas de la familia GH18, similar al dominio EndoE perteneciente a Enterococcus faecalis. Las enzimas GH18 contienen una secuencia consenso conservada motivo (LIVMFY) - (DN) -G- (LIVMF) - (DN) - (LIVMF) - (DN) -X-E, donde el ácido glutámico terminal es esencial para la actividad enzimática. Al alinear el sitio activo GH18 en CP40, quedo establecida su similitud con las enzimas EndoE y EndoS, solo con cambios en uno o dos aminoácidos respectivamente. La función como factor de virulencia se ha asociado a la capacidad demostrada in vitro de degradar la región Fc de los anticuerpos IgG. La endoglicosidasa CP40 no hidroliza los glicanos en la IgG bovina y caprina, mientras que la IgG ovina se hidroliza de manera parcial y la IgG equina por completo. También se realizó el análisis con subclases de IgG humano, presentando actividad en todas y de manera parcial en IgG4. No hubo actividad enzimática detectable en otras glicoproteínas, incluido algunos de los otros isotipos de inmunoglobulina ( $\operatorname{IgA}, \operatorname{IgD}$ y $\operatorname{IgE})^{(48)}$.

\section{Proteínas secretadas PLD y CP40}

Según varios informes, las proteínas exportadas o secretadas por las bacterias participan activamente en el proceso de infección ${ }^{(49)}$. Por tal motivo, la expresión y secreción de las proteínas PLD y CP40 han sido sumamente estudiadas. El desarrollo de una infección experimental evidenció mediante inmunoblot que la producción de anticuerpos estuvo dirigida en un $88 \%$ al reconocimiento de proteínas de 30-31Kda (PLD) y en un 75 a $88 \%$ hacia proteínas de $38-41 \mathrm{KDa}(\mathrm{CP} 40)$, rango en el que se encuentran ambas proteínas ${ }^{(50)}$. La cepa 1002 atenuada, tras varios pases en un modelo murino fue capaz de revertir la virulencia. El análisis por espectrometría de masas permitió la identificación de las proteínas PLD y CP40 únicamente, en la cepa 1002 reactivada, lo que indica la participación de estas proteínas en la virulencia ${ }^{(51)}$. Por otra parte, a través de PCR en tiempo real se identificó in vitro e in vivo la expresión de varios genes involucrados en la virulencia entre ellos pld y cp40. Este análisis permitió constatar que en las cepas aisladas de nódulos linfáticos la expresión de estos genes fue superior en comparación con las cepas obtenidas de cultivos in vitro ${ }^{(52)}$ 


\section{Factores de virulencia involucrados en la adquisición de hierro}

En la PiCp1 se encuentra el operón (fag $\mathrm{ABCD})^{(29)}$, compuesto por cuatro genes $f a g A$, fagB, $f a g C$, fagD que se encuentran ubicados corriente abajo del gen pld. Estos genes codifican respectivamente para una proteína integral de membrana, una enterobactina transportadora de hierro, una proteína de membrana citoplasmática de unión a ATP y una proteína siderófora de unión a hierro. La FagA fue identificada como proteína de asociación a membrana con potencialidades patogénicas, mediante el análisis por espectrometría de masas de las proteínas expresadas en una cepa de $C$. pseudotuberculosis cultivada con suero animal ${ }^{(53)}$. El cultivo de $C$. pseudotuberculosis en medios con quelantes de hierro (dipiridilo), provocó la disminución en un orden de logaritmo en el conteo de unidades formadoras de colonias (UFC), en comparación con las bacterias crecidas en medios enriquecidos con hierro. La evaluación de la respuesta transcripcional de C. pseudotuberculosis, con restricción de hierro, permitió identificar la regulación negativa de genes que participan en el metabolismo energético del ciclo de Krebs $(s d h C, s d h B, l p d)$, producción de ATP (atpF, atpH), metabolismo del piruvato (lpd), fosforilación oxidativa ( $q c r C, q c r A, q c r B, c t a C, c t a F, c t a E$, $c t a D)$, procesos del ribosoma, transporte (rplJ, rplL, rplM, rpmA, rpsC, rpsI, rpsL, rpsM) у factores de alargamiento EF-G y EF-Ts asociados a la traducción del RNAm (fusA, tsf). Se identificó el gen análogo a $d t x R$ de $C$. diphteriae, con un $79 \%$ de similitud en la secuencia, que codifica para una proteína dependiente de unión a hierro, que actúa como factor de regulación de más de 40 genes ${ }^{(54)}$. En PiCp3 y PiCp4 se han estudiado los genes pertenecientes al operón ciuABCDE involucrados en la absorción de hierro, transporte y biosíntesis de sideróforo $^{(29)}$.

\section{Proteína TetA}

En PiCp2 el gen tetA codifica una proteína transportadora de eflujo de tetraciclina que protege ante la acción de este antibiótico y confiere resistencia a la bacteria. El gen tetA a menudo es transportado por elementos transmisibles como plásmidos, transposones e integrones y ha sido identificado en C. pseudotuberculosis ${ }^{(29)}$.

\section{Factores de virulencia para la infección de macrófagos}

En la isla de patogenicidad $\mathrm{PiCp} 2$ se encuentran los genes $\operatorname{pot} G, \operatorname{sig} K$ y $\operatorname{dip} Z$, que responden a los mecanismos responsables del estilo de vida intramacrofágico de C. pseudotuberculosis. El gen pot $G$ codifica para una proteína de membrana de unión a ATP que proporciona energía para absorción de putrescina (poliamina) desde el espacio periplásmico, funciona como sistema transportador de putrescinas ${ }^{(29)}$. Las putrescinas son poliamidas producidas por los macrófagos que inducen la disminución de la producción de especies reactivas del nitrógeno y la síntesis de citocinas pro-inflamatorias. El gen dipZ se ha identificado en el filum 
Actinobacteria, está regulado por sigK ${ }^{(55)}$ y se activa durante la infección de macrófagos por Mycobacterium tuberculosis. En la PiCp4 la presencia del gen que codifica para el factor Sigma, confiere capacidad de proteger ante estrés oxidativo, específicamente ante la acción de los productos intermediarios del nitrógeno, producidos por los macrófagos ${ }^{(56)}$.

La cepa FCR41 de C. pseudotuberculosis fue empleada en el estudio de los genes relacionados con la síntesis del pili. La estructura del pili está compuesta por el pili mayor SpaA y SpaD; el pili menor SpaB y SpaE; y el pilli tipo, SpaC, SpaF. Una estructura completa de pili o incluso el pili menor pueden realizar un contacto inicial con receptores de las células hospederas, para facilitar la entrada del microrganismo. En esta cepa se identificó el gen spaC, que codifica para una proteína responsable del anclaje del pili a la pared celular, que puede permitir el contacto inicial con los receptores de la célula, para luego facilitar la invasión intracelular. También presentó el gen $n a m H$, que codifica para una neuroaminidasa extracelular, que catalizan la eliminación de los grupos de ácido siálico presentes en una gran variedad de glicoconjugados de la matriz extracelular de la célula del hospedero, lo que favorece la adherencia a las células. En FCR41 se detectó el gen $\operatorname{sod} C$, que codifica para una superóxido dismutasa, enzima anclada a la membrana con dominio extracelular, que elimina los radicales libres del oxígeno productos del estallido respiratorio en los macrófagos ${ }^{(57)}$.

\section{Factores de virulencia de resistencia y adaptación}

Las proteínas chaperonas (HSP) son altamente conservadas y se expresan ante el estrés térmico, así como la diminución de nutrientes, hipotaxia, ruptura del metabolismo y otros procesos celulares. En C. pseudotuberculosis han sido estudiadas la Hsp10 (groES) y Hsp60 $(\text { groEL })^{(58)}$. En la cepa 1002, se evaluó la resistencia a diversos tipos de estrés abióticos, tales como acidez, altas temperaturas y estrés osmótico, asociado a la presencia de estas proteínas ${ }^{(59)}$. El gen $h s p R$, codifica para el factor de regulación de la expresión (proteína represora) del operón con los genes $d n a K$, grpE, dnaJ y $h s p R$, que codifican proteínas de choque térmico. En ausencia de estrés, la proteína HspR se une a una secuencia de repetición invertida que reprime a los promotores responsables de controlar la expresión del operón Hsp. En otro estudio la separación de proteínas mediante electroforesis bidimensional, permitió identificar 11 proteínas extracelulares nuevas, 3 con funciones desconocidas y 8 relacionadas con el factor de alargamiento Tu, GroEL (HSP60), enolasa, deshidrogenasa de gliceraldehído-3-fosfato y superóxido dismutasa ( $\operatorname{SodA}$ ), los cuales dependen de un método de secreción no clásico vía SecA. Ambos genes SecA (SecA1 y SecA2), se identificaron en las cepas estudiadas, posiblemente involucrados en el sistema de secreción de $C$. pseudotuberculosis ${ }^{(60)}$. Aun se continúa con el estudio de los factores de virulencia de $C$. pseudotuberculosis como moléculas candidatas para el desarrollo de vacunas más potentes y eficaces. 


\section{Patogénesis y mecanismos de evasión del sistema inmune}

La manifestación cutánea de la LAC se caracteriza por la formación de abscesos en nódulos linfáticos subcutáneos, los cuales son visibles y palpables a través de la piel y su localización depende del punto de entrada del microorganismo. Las lesiones pueden aparecer como abscesos organizados, con inflamación, encapsulación fibrosa, pérdida de pelo sobrepuesto y ruptura eventual, dando como resultado la descarga de contenido purulento. En la forma visceral, los abscesos tienen lugar en los nódulos linfáticos internos, así como en pulmones, hígado y riñones, causando deterioro en la condición orgánica del animal hacia el desarrollo de un curso crónico ${ }^{(61)}$. En las formas atípicas de la enfermedad, las lesiones macroscópicas no se corresponden con nódulos caseosos, describiéndose la toxemia neonatal o icterohemoglobinuria de recién nacidos, artrosinovitis, endometritis, mastitis y orquitis ${ }^{(62)}$.

La infección se inicia con el ingreso de la bacteria a través de lesiones en la piel generadas durante el manejo de los ovinos, como cortes de cola, marcaje de orejas, castración, esquila o en algunos casos, lesiones generadas durante la alimentación con forraje espinoso que dañan la mucosa oral. Los baños sanitarios también contribuyen a la infección, favoreciendo la entrada del microorganismo a través de pequeñas heridas de la piel ${ }^{(1)}$. La infección primaria ocurre en el sitio de ingreso de la bacteria, con diseminación hematógena y linfática formando abscesos en los nódulos linfáticos más cercanos al sitio de infección (parotídeos, submandibulares, prefemorales, preescapulares, poplíteos o mamarios). Luego ocurre una infección secundaria con la formación de abscesos en ganglios linfáticos (torácicos, bronquiales y mediastínicos) y diversos órganos ${ }^{(63,64)}$. En ovinos la apariencia morfológica de los nódulos abscedados es la característica de capa de cebolla al presentar una distribución en láminas concéntricas fibrosas separadas por material caseoso. En las cabras los nódulos afectados usualmente forman una pasta purulenta uniforme seca. Esta diferencia podría deberse a la naturaleza de las enzimas fagocíticas, siendo en las cabras de mayor actividad lítica que en las ovejas ${ }^{(8,9)}$.

Los mecanismos involucrados en la adherencia y supervivencia intracelular de $C$. pseudotuberculosis en células no fagocíticas aún siguen siendo objeto de estudio por diversos investigadores. En estudios in vitro $C$. pseudotuberculosis fue capaz de adherirse e invadir la línea fibroblástica de células embrionarias de riñón ovino FLK-BLV-044, con replicación celular durante $24 \mathrm{~h}$ y viabilidad bacteriana de 120 h, con una correlación positiva entre la tasa de adherencia e invasión ${ }^{(65)}$. Estos resultados sugieren que la instauración de la infección, así como la persistencia, pueden estar favorecidas por la infección intracelular en tejido del sitio de entrada del microorganismo y no solo por la infección de células fagocíticas. $C$. pseudotuberculosis es fagocitada por los macrófagos que son reclutados al sitio de infección, y se ha demostrado que tienen la capacidad de permanecer viables dentro de estos hasta por $72 \mathrm{~h}$, evadiendo los mecanismos de eliminación de patógenos que presentan los 
macrófagos ${ }^{(66)}$. Los macrófagos infectados con C. pseudotuberculosis activan la producción de compuestos intermediarios reactivos del oxígeno (ROI), los cuales provocan daños a nivel de ADN. La unión de las bacterias a los receptores de la membrana del fagosoma del macrófago provoca el denominado estallido respiratorio que favorece la producción de $\mathrm{NADH}$. Antes de que el lisosoma se fusione con el fagosoma, en este último, tiene lugar una reducción de oxígeno molecular $\left(\mathrm{O}_{2}\right)$ catalizada por la NADPH-oxidasa presente en la membrana del fagosoma. El anión superóxido resultante $\left(\mathrm{O}_{2}^{-}\right)$es tóxico para la bacteria, pero a su vez da lugar a otros radicales tóxicos de vida corta, como el peróxido de hidrógeno $\left(\mathrm{H}_{2} \mathrm{O}_{2}\right)$, el radical hidroxilo $(\mathrm{OH})$ y el oxígeno singlete $\left(\mathrm{O}^{1}{ }_{2}\right)$. Cuando el lisosoma se fusiona con el fagosoma, se libera la enzima mieloperoxidasa, que actúa sobre los peróxidos en presencia de haluros $\left(\mathrm{I}^{-} \mathrm{y} \mathrm{Cl}^{-}\right.$), para producir compuestos halogenados (hipohaluros) muy tóxicos y de vida larga: ácido hipocloroso $(\mathrm{ClOH})$ e hipoiodoso ${ }^{(66)}$. Sin embargo, $C$. pseudotuberculosis ha desarrollado mecanismos de resistencia para protegerse ante los radicales libres del $\mathrm{O}_{2}$.

Las superóxido dismutasas (SODs) constituyen una familia de tres metaloenzimas (FeSOD, MnSOD y CuZnSOD) con diferente localización intracelular y distribución, que catalizan la conversión de los radicales superóxido en $\mathrm{H}_{2} \mathrm{O}$ y $\mathrm{O}_{2}$. Se ha comprobado la presencia de $\mathrm{Mn} / \mathrm{FeSODs}$ en $C$. pseudotuberculosis y el análisis filogenético permitió establecer las diferencias y similitudes evolutivas de las secuencias de esta enzima en hospederos de la especie ovina, caprina, bovina, equina y el humano, así como con diferentes especies de Corynebacterium. Esto explicaría la capacidad que presenta una misma cepa de $C$. pseudotuberculosis biovar ovis de permanecer en macrófagos de diferentes tipos de hospederos $^{(67)}$. C. pseudotuberculosis presenta la enzima catalasa ${ }^{(1)}$ que brinda protección ante la acción del $\mathrm{H}_{2} \mathrm{O}_{2}$, ya que lo descomponen en $\mathrm{H}_{2} \mathrm{O}$ y $\mathrm{O}_{2}$. También los productos intermediarios de la enzima durante la reacción de dismutación, pueden unirse a NADPH oxidasa, lo que funciona como regulador de la actividad enzimática y disminuye la formación de otros productos del estrés oxidativo como el radical hidroxilo y el oxígeno singlete $\left(\mathrm{O}_{2}^{1}\right)$.

También en los macrófagos actúan como otro mecanismo de eliminación de patógenos los productos reactivos del nitrógeno (RNI). El estudio in vitro de cepas de $C$. pseudotuberculosis mutantes del factor sigma, fueron más susceptibles a concentraciones de óxido nítrico, por lo que se propone que la presencia de éste, proteja ante este tipo de estrés oxidativo $^{(56)}$. La presencia de ácidos corynomicólicos le otorga a $C$. pseudotuberculosis protección mecánica y posiblemente bioquímica, permitiéndole resistir la digestión por enzimas hidrolíticas presentes en los lisosomas y la acción de proteínas antimicrobianas ${ }^{(66)}$. La inoculación de extractos de ácidos corynomicólicos, en cabras hembras, causó hemorragia, congestión, degeneración, necrosis, edema e infiltraciones leucocíticas en órganos reproductores y en ganglios linfáticos asociados, así como aumentó la concentración de hormonas estrogénicas ${ }^{(62)}$. También se han asociado con disminución de testosterona y pérdida de calidad del semen, con aumento en producción de citocinas pro-inflamatorias ${ }^{(5)}$. 
La exotoxina PLD cataliza la disociación de la esfingomielina componente importante de las membranas celulares, cuya hidrólisis provoca la lisis celular incrementando la permeabilidad vascular, con la consecuente formación de edemas ${ }^{(1)}$. La PLD actúa directamente sobre las células endoteliales en el entorno del punto de infección y en los macrófagos una vez que ha sido fagocitada la bacteria. La acción de esta toxina facilita la colonización, la diseminación regional y sistémica de la bacteria, con la generación de abscesos en los nódulos linfáticos ${ }^{(66)}$.

Las bacterias no controladas por la pared del absceso entran en los capilares y forman colonias que ocluyen a los vasos sanguíneos, generando isquemia que, junto a las toxinas, destruyen las células del tejido sano, aumentando la masa necrótica. Las bacterias viables se diseminan a través de los vasos linfáticos y penetran otros linfonodos y vasos sanguíneos, llegando a diferentes órganos donde se repite la formación de abscesos. Este comportamiento origina las manifestaciones clínicas de la enfermedad de tipo visceral, que afecta nódulos linfáticos internos y órganos especialmente pulmones e hígado ${ }^{(61,64)}$.

C. pseudotuberculosis se libera del interior de las células como resultado de un proceso que conlleva a la muerte de los fagocitos. Aunque los mecanismos específicos aún no están claros, se plantea que la muerte celular de los macrófagos no es inducida por la autofagia o la apoptosis. Estudios realizados in vitro mediante la infección de la línea de macrófagos J774 con C. pseudotuberculosis, permitió determinar que los niveles de la proteína I asociada a microtubulos de cadena ligera 3 (mecanismo de autofagia) y la actividad de la caspasa-3 (mecanismo de apoptosis), se mantuvieron estables sin variación en las células infectadas ${ }^{(25)}$. En otros trabajos la necrosis se ha visto favorecida en vez de la apoptosis, en macrófagos infectados con C. pseudotuberculosis, provocando cambios degenerativos como la ruptura de la membrana plasmática, alteraciones en las mitocondrias, cambios en la envoltura nuclear, dilatación de la envoltura del núcleo y de la membrana del retículo endoplásmico rugoso y formación de vesículas en el citoplasma ${ }^{(68,69)}$.

Otra característica de la enfermedad es la formación de piogranulomas, como resultado del crecimiento bacteriano incontrolado dentro de los macrófagos, el hospedero intenta restringir y limitar la infección a través de la formación de estas estructuras. Los estudios inmunohistoquímicos sobre la composición celular de las lesiones pulmonares en ovejas infectadas por $C$. pseudotuberculosis han puesto de manifiesto un predominio de macrófagos grandes en las paredes del absceso y rodeando el parénquima pulmonar, con expresión de moléculas del complejo principal de histocompatibilidad de clase II (MHC). Los linfocitos $\mathrm{T}$ fueron prominentes en las lesiones, mientras que los linfocitos $\mathrm{B}$ y granulocitos comprendían una porción menor en los infiltrados celulares. Dentro de las lesiones encapsuladas se encontraron linfocitos y células MHC clase II en el centro de la masa necrótica. Rodeando esta región se identificaron células $\mathrm{CD}^{+}$, así como células $\mathrm{CD}^{+}$y $\mathrm{CD}^{+}$distribuidas a través del tejido linfático. Generalmente en las lesiones caseosa inmaduras se encuentran linfocitos $\mathrm{CD}^{+}$y en las lesiones más desarrolladas la concentración 
de células $\mathrm{CD}^{+}$es predominante, lo que se relaciona con el mecanismo del sistema inmune para combatir la diseminación de los macrófagos infectados ${ }^{(70,71)}$.

En cabras los cambios histopatológicos observados en el tracto reproductivo y nódulos linfáticos después de la inoculación experimental con C. pseudotuberculosis, revelaron infiltración leucocítica, así como congestión generalizada, degeneración, infiltración de células del estroma y necrosis en los ovarios ${ }^{(71)}$. El estudio de la respuesta del sistema inmune en un modelo experimental permitió establecer que la respuesta humoral comienza entre el día 6 y 11 post infección. A partir del día 5 de la infección se produce la expresión de IFN- $\gamma$ con valores de 0.5 a 1.0 (DO450), seguido de una segunda producción a partir del día 16 post-infección con máximos de 2.5 a 3.0, valores elevados que se mantienen hasta el día 4256 de la infección, donde empieza a decaer la respuesta. La producción primaria de IFN- $\gamma$ se ha asociado con la respuesta innata que involucra células NK, mientras que la respuesta secundaria de mayor duración se asocia con la respuesta inmune adquirida con la participación de células $\mathrm{T}^{(70)}$. La producción de citoquinas pro-inflamatorias TNF- $\alpha$ e IL6 tienen lugar en el sitio de inoculación, mientras que el IFN- $\gamma$ se encuentra en los linfonódulos drenados ${ }^{(72)}$.

\section{Vacunas comerciales}

La mayoría de las vacunas comerciales disponibles para LAC están compuestas por formulaciones polivalentes, presentando una combinación de antígenos de varios agentes patógenos incluyendo exotoxina PLD, considerada el antígeno con mayor capacidad inmunogénica para $C$. pseudotuberculosis ${ }^{(11,27)}$. Han sido empleadas desde hace varias décadas, sin embargo aún no se encuentran disponibles en todos los países productores de pequeños rumiantes, incluido México.

La vacuna Glanvac 3 (Zoetis, London) ${ }^{(73)}$, combina toxinas de CIostridium perfringens Tipo D, Clostridium tetani y C. pseudotuberculosis y evaluada en ovinos del Reino Unido, informó que solo el $20.8 \%$ del total de seis animales vacunados y desafiados con una cepa virulenta, presentaron lesiones de donde se aisló la bacteria. La vacuna Glanvac 6 (Zoetis, West Ryde, Australia), presenta una formulación multicomponente que incluye toxinas de $C$. pseudotuberculosis, Clostridium perfringens tipo D, Clostridium tetani, Clostridium novy tipo $B$, Clostridium septicum y Clostridium chauvoei. Esta vacuna reduce las manifestaciones clínicas de la enfermedad y el desarrollo de lesiones pulmonares ${ }^{(8,13)}$. En Australia es administrada tanto a ovejas como cabras, y varios ensayos de campo han mostrado tasas de protección variables, con valores que van desde 25 hasta $90 \%$ del total del rebaño. En 1995 la prevalencia promedio de LAC en ovejas adultas en rebaños vacunados era de $97 \%$ en Nueva Gales del Sur, $91 \%$ en Victoria y el 88 \% en Australia Occidental. Para el 2003 la prevalencia promedio estimada de LAC en la población de ovejas adultas había disminuido 
a $29 \%$ en Nueva Gales del Sur, $26 \%$ en Victoria y $20 \%$ en Australia Occidental; y de un $26 \%$ en general a $5.9 \%$ en el 2009. Además, el estudio permitió establecer que solo el $43 \%$ de los productores usaban la vacuna y de estos solo el $12 \%$ seguían de manera adecuada las indicaciones del fabricante ${ }^{(6,12)}$. Sin embargo, estas vacunas de la serie Glanvac no impiden la infección, y presentan reacciones adversas con formación de granulomas cutáneos en el sitio de la inyección, tanto en ovejas como en cabras, con choque anafilácticos en esta última $^{(7,8)}$. En Canadá en 1998 se realizó una evaluación de la eficacia de Glanvac 6 en comparación con la vacuna comercial Case-Bac (Colorado Serum, EUA), y una vacuna experimental compuesta por muramil dipéptido. La vacuna Glanvac 6 y la vacuna experimental presentaron un mayor título de anticuerpos que Case-Bac, durante 6 a 12 meses; sin embargo, Glanvac 6 provocó un elevado número de manifestaciones de alergia en el sitio de inoculación ${ }^{(74)}$.

La vacuna Caseous D-T (Colorado Serum, EUA) compuesta por toxinas de Clostridium perfringens tipo D, Clostridium tetani y cultivos totales inactivados de C. pseudotuberculosis en combinación con PLD, se ha empleado en Estados Unidos, demostrando que ayuda a disminuir la presencia de abscesos internos y externos, aunque con efectos secundarios como leve cojera (dolor) en corderos y letargo, en un porcentaje elevado de los animales maduros. Por otra parte, la vacuna Case-Bac (Colorado Serum, EUA), compuesta por toxina PLD, ha sido utilizada fundamentalmente en ovejas. Esta vacuna también ocasiona reacciones adversas en el sitio de inoculación, letargo, rigidez y fiebre, siendo estos síntomas más severos en cabras, incluyendo manifestaciones de edema ventral, ataxia y convulsiones, lo que conlleva a que este profiláctico no esté aprobado para su uso en esta especie. El empleo de esta vacuna en ovejas, redujo la formación de abscesos, donde solo 10 de un total de 18 animales presentaron abscesos externos en comparación con el grupo control donde todos desarrollaron estas lesiones. Por otra parte solo 2 de las 18 ovejas vacunadas tenían abscesos internos, mientras que 9 de cada 10 ovejas de control tenían abscesos internos ${ }^{(8,9)}$.

En España la compañía Zoetis comercializa la vacuna Biodectin ${ }^{\mathrm{TM}}$, la cual está compuesta por seis fracciones antigénicas: Clostridium septicum, Clostridium novyi Tipo B, Clostridium tetani, Clostridium perfringens Tipo D, C. pseudotuberculosis y Clostridium chauvoei, hidróxido de aluminio, Tiomersal y Moxidectina (compuesto con actividad antiparasitaria) ${ }^{(75)}$. También existen vacunas comerciales elaboradas a partir de cepas vivas atenuadas, como LinfoVac (Laboratorios Vencofarma do Brasil), desarrollado por la Empresa Baiana de Desarrollo Agrícola (www.ebda.ba.gov.br) en colaboración con el Instituto de Ciencias de la Salud de la Universidad Federal de Bahía, que contiene la cepa viva atenuada 1002 de C. pseudotuberculosis y su uso está autorizado en Brasil. Estudios experimentales en un modelo murino indicó que la protección que confiere esta vacuna es de $80 \%{ }^{(10)}$. 
La protección proporcionada por las vacunas comerciales está asociada a la producción de anticuerpos anti-exotoxina PLD, los cuales protegen contra el daño tisular y la diseminación del microorganismo. Sin embargo, confieren una protección parcial, ya que estas vacunas no favorecen la activación de la respuesta inmune celular, principalmente de tipo T citotóxicas necesaria para eliminar las bacterias intracelulares. Por tal motivo diferentes grupos de investigadores han trabajo en el desarrollo de vacunas experimentales que permitan mejorar la protección.

\section{Vacunas experimentales}

\section{Vacunas inactivadas y toxoides}

Las vacunas inactivadas están compuestas por cultivos totales de la bacteria no viables o toxinas inactivadas, ya sea por métodos químicos o físicos. En estas formulaciones el microrganismo se encuentra muerto por lo que no confieren peligro de desarrollo de la enfermedad; sin embargo, la respuesta principalmente es de tipo humoral, menos intensa, requiere de altas concentraciones del microorganismo y de varias dosis. No son sometidas a ningún procedimiento de purificación, por lo que contienen todos los componentes bioquímicos de la bacteria los cuales son más reactógenos y pueden producir efectos adversos. El precipitado proteico de una cepa de $C$. pseudotuberculosis aislada de alpaca en Perú, se evaluó en un grupo de 20 ratones BALB/c, donde indujo protección ante el desafío con $10^{4}$ UFC de una cepa virulenta de C. pseudotuberculosis. La vacuna redujo los efectos tóxicos provocados por la bacteria, lo cual se observó con la disminución del número y tamaño de abscesos en los animales del grupo vacunado (40 \% afectado) en comparación con los múltiples abscesos de mayor tamaño a nivel subcutáneo y en riñón e hígado, en los animales del grupo control (95\% afectado) ${ }^{(76)}$.

Las formulaciones vacunales en base a $250-500 \mathrm{mg} / \mathrm{ml}$ de pared celular y $133-265 \mathrm{mg} / \mathrm{ml}$ de toxina PLD, todas suplementadas con $20 \mathrm{mg} / \mathrm{ml}$ de muramil dipéptido como adyuvante, fueron evaluadas en alpacas, sometidas al desafío con $10^{6}$ UFC de una cepa virulenta de $C$. pseudotuberculosis. Los animales vacunados con la mayor dosis de PLD no mostraron abscesos a diferencia del grupo vacunado con la menor concentración, donde se observó la formación de abscesos en el sitio de inoculación y en linfonodos renales. Las formulaciones que incluyeron pared celular mostraron un menor grado de protección, con formación de abscesos superficiales e internos. Los resultados sugieren que la concentración de toxina PLD, puede influir en la capacidad protectora, siendo dosis dependiente en la inmunización de $\operatorname{alpacas}^{(77)}$.

El grado de protección conferido por la vacunación con toxina PLD adsorbida en gel de hidróxido de aluminio (Grupo 1) o su combinación con toxinas de Clostridium perfringens 
D, Clostridium novyi B, Clostridium tetani, Clostridium septicum y Clostridium chauvoei (Grupo 2), así como toxinas de Clostridium spp., PLD y $1.2 \mathrm{mg} / \mathrm{ml}$ de selenato de sodio (Grupo 3); fue evaluado en un modelo ovino, desafiado con 1.3 x $10^{8}$ UFC de una cepa virulenta de $C$. pseudotuberculosis. El porciento de animales afectados en el grupo 1 fue de $10.5 \%$ (4 de 38 animales mostraron una lesión superficial), para el grupo 2 de $7.9 \%$ (3 de 38 animales mostraron una lesión superficial) y de $8.3 \%$ en el grupo 3 ( 2 de 24 animales), cada uno con una lesión superficial y a nivel de pulmón, en contraste con los resultados obtenidos en el grupo control de animales no vacunado con afectación del $51.5 \%$ (17/33) con 60 lesiones a nivel de pulmón y 16 en carcasas, con 4.5 lesiones por animal. Los resultados indicaron que no hubo depresión de la potencia protectora como resultado de la combinación de PLD con los antígenos de Clostridium $^{(78)}$.

La eficacia de cuatro vacunas no comerciales en base a PLD como antígeno se evaluó en ovinos desafiados con una cepa virulenta. Los niveles de iones superóxido se determinaron como respuesta inmune inespecífica, siendo estos elevados en el grupo vacunado con PLD + bacteria inactivada, seguido del grupo vacunado con Toxoide PLD. La actividad de lisozimas fue superior en el grupo vacunado con PLD + bacteria inactivada, seguido de Toxoide PLD, PLD + vacuna comercial Covexin8 y una vacuna experimental local. El grupo vacunado solo con PLD mostró una marcada respuesta positiva de proliferación de linfocitos en comparación con el resto de los grupos. Los resultados indicaron que la PLD estimuló la respuesta inmune celular específica e inespecífica ${ }^{(79)}$.

Cuatro extractos antigénicos diferentes obtenidos de la cepa atenuada $\mathrm{T} 1$, fueron evaluados en cabras de raza Canindé, para el estudio de la respuesta inmune humoral y celular. Los animales del grupo 1 (inmunizados con $0.5 \mathrm{ml}$ del sobrenadante de cultivo de la cepa T1 en proporción 1:1 con adyuvante incompleto de Freund, AIF) y grupo 3 (inmunizados con 100 $\mathrm{mg}$ de concentrado extracelular, $250 \mathrm{mg}$ de oligodesoxinucleótidos $\mathrm{CpG}$ y $0.5 \mathrm{ml}$ de adyuvante AIF); mostraron los niveles de anticuerpos e IFN- $\gamma$ más elevados luego de la inmunización, así como post-desafío con $10^{5}$ UFC de la cepa virulenta VD57, en comparación con los grupos 2 (1 ml de suspensión de $2 \times 10^{6} \mathrm{UFC} / \mathrm{ml}$ cepa T1), grupo 4 (formulación del grupo 3 sin AIF) y grupo 5 control. Solo el $25 \%$ de los animales del grupo 1 , el $33.3 \%$ del grupo 2 y $22.2 \%$ del grupo 3 no desarrollaron lesiones, en el grupo 4 y 5 el $100 \%$ de los animales desarrollo algún tipo de lesión ${ }^{(80)}$. Estos resultados evidencian que la producción de anticuerpos específicos anti-PLD solo disminuye la diseminación de la bacteria y aparición de lesiones en tejidos diferentes al sitio de inoculación, no controlando la infección. Las vacunas de tipo bacterinas o toxoides, contribuyen a disminuir las manifestaciones clínicas de la enfermedad, siendo más eficientes en ovinos que caprinos, aunque en ninguna de las dos especies se logra controlar la infección, quedando un porciento de animales afectados que pueden propagar la enfermedad. 


\section{Vacunas atenuadas}

Las vacunas atenuadas presentan agentes inmunizantes vivos que pueden replicarse en el organismo sin causar la enfermedad, ya que carecen de determinadas estructuras o moléculas que disminuyen su virulencia. En principio confieren una respuesta inmune muy intensa y de larga duración, ya que dan lugar a una infección similar a la natural, pero constituyen un riesgo, ya que en algunos casos puede revertirse la virulencia. Las primeras vacunas atenuadas experimentales para LAC empleaban una cepa denominada Toxminus, cuyo gen pld se modificó mediante mutación sitio específica. La necropsia de los animales vacunados con $10^{5}$ a $10^{7}$ UFC de la cepa atenuada Toxminus, permitió observar que no se formaron abscesos en los animales desafiados con $10^{6}$ UFC de una cepa virulenta, en comparación con el grupo control donde se desarrollaron abscesos de $2.5 \mathrm{~cm}$ en ganglios poplíteo. Sin embargo, la vacuna produjo un absceso indeseable en el sitio de inoculación, el título de anticuerpos en los grupos vacunados con $10^{5}$ a $10^{7} \mathrm{UFC}$ fue similar, por lo que la respuesta no fue dosis dependiente y la cepa virulenta de desafío indujo una respuesta de anticuerpos superior en las semanas 5 y 9. También hubo una reducción en la capacidad de la cepa Toxminus de permanecer en el hospedero, debido a la ausencia de PLD, antígeno que favorece la persistencia, además de activar de manera elevada la respuesta inmune humoral $^{(81)}$.

En otro estudio se transformó la cepa Toxminus con un plásmido que contenía el gen de pld modificado para la obtención de la exotoxina con un cambio de histidina por un triptófano en la posición 20, lo que elimina la actividad enzimática. La inmunización con la cepa Toxminus administrada vía oral, indujo una respuesta humoral predominante de tipo IgG1, mientras que los niveles del isotipo IgG2 fueron superiores en ovejas vacunadas vía subcutánea. Las células Th1 son responsables de la inmunidad celular mediada por células, producen IFN- $\gamma$, IL-2 y factor de necrosis tumoral beta (TNF- $\beta$ ), citoquinas que activan macrófago y complementan la activación de los linfocitos B para la producción de anticuerpos del isotipo IgG2. Por otra parte, los clones Th2 secretan IL-4 y preferentemente inducen en las células B la producción de $\operatorname{IgG1}$, IgA e IgE. En consecuencia, con los resultados obtenidos, los animales vacunados vía oral no presentaron niveles significativos de protección, debido a que el aumento en IgG1 es indicativo de ausencia de una respuesta Th1, la cual es fundamental para la activación de célula T citotóxicas, esenciales para la eliminación de patógenos intracelulares, como C. pseudotuberculosis. La incidencia y el grado de formación de abscesos fueron muy reducidos (abscesos de $0.2 \mathrm{~cm} \mathrm{y} 1 \mathrm{~cm}$ ), presentándose solo en dos animales en el sitio de inoculación de la cepa virulenta para el desafío. En el grupo de animales vacunados con la cepa Toxminus no modificada, el $50 \%$ de las ovejas desarrollaron abscesos, así como también el $66 \%$ de animales del grupo control no vacunado. La cepa Toxminus no permitió una expresión elevada de PLD y se encontró evidencia de la excreción de la bacteria viva atenuada a través de las heces ${ }^{(82)}$. 
La cepa CZ171053 mutada en el gen ciuA, mediante el sistema tramposon-TnFuZ, presentó una capacidad reducida para sobrevivir in vitro dentro de los macrófagos de la línea celular J774. La inmunización de ratones BALB/c con esta cepa atenuada, permitió la sobrevivencia del $80 \%$ de los animales desafiados con $10^{6}$ UFC de la cepa virulenta MIC-6. Estos resultados sugieren que la cepa CZ171053 podría evaluarse como vacuna viva atenuada en los hospederos diana de la enfermedad.

El comportamiento de la respuesta inmune humoral y celular se evaluó en ratones BALB/c inoculados con $10^{7}$ UFC de la cepa atenuada T1. Se observó un aumento en el título de IgG1 e IgG2, no se mostraron lesiones características de la enfermedad y el cultivo de las células del bazo, estimuladas in vitro con antígenos secretados por T1, presentaron una mayor proliferación en comparación con las células estimuladas con antígenos intracelulares ${ }^{(83)}$.

\section{Vacunas de ADN}

Los avances en las técnicas de biología molecular han permitido el desarrollo de vacunas de nueva generación, dentro de las que se encuentran las vacunas de ADN desnudo. Estas vacunas son solo de $\mathrm{ADN}$ (plásmidos con los genes de interés), no cuentan con envolturas o estructuras proteicas, por lo que es muy importante la ruta de administración, la dosis, y la re-inmunización, ya que son factores que influyen en la potencia y el tipo de respuesta inmune. La desventaja de este tipo de vacunas radica en la capacidad de expresar el antígeno de interés, ya que en la mayoría de los casos las partículas presentan una baja adsorción y la cantidad de plásmidos que se introduce en las células es limitada.

El diseño de un plásmido portador del gen que codifica para el dominio extracelular de CTLA-4 bovino fusionado al gen pld inactivado (boCTLA-4-HIg- $\triangle$ PLD) se evaluó como vacuna de ADN desnudo en ovinos. El CTLA-4 se une con alta afinidad al antígeno de membrana B7 en células presentadoras de antígeno (APC), mejorando la respuesta inmune humoral. Aunque aumentó el título de anticuerpos significativamente, la protección de los ovinos inmunizados fue parcial ante el desafío experimental con una cepa virulenta ${ }^{(84)}$. Diferentes vías de inmunización fueron evaluadas: intramuscular, subcutánea y bombardeo con pistola génica. Los niveles máximos de anticuerpos $\operatorname{IgG}$ totales fueron de $12 \times 10^{3}$ en el grupo vacunado vía intramuscular, mientras que en los grupos con las otras vías de administración se alcanzaron valores de 3-4 x 10 3 . La protección conferida por la vacuna administrada vía intramuscular fue de un $45 \%$ (9 de 20 animales), en comparación con el resto de los grupos (vía subcutánea y pistola génica) que solo protegieron al $10 \%$ de los animales $^{(85) \text {. }}$

El potencial de una vacuna de ADN formulada en base al plásmido pTARGET transformado con la proteína esterasa cp09720(86), se comparó con una vacuna de subunidades con 
CP09720 recombinante adyuvada con hidróxido de aluminio. Ambas se evaluaron en ratones $\mathrm{BALB} / \mathrm{c}$, siendo la vacuna de proteína recombinante la que indujo mayor título de anticuerpos IgG1 e IgG2. Las dos vacunas fueron capaces de aumentar la expresión de IFN$\gamma$, aunque la vacuna de subunidades presentó los niveles más altos de ARNm de IFN- $\gamma$. Los niveles de protección ante el desafío fueron de $58.3 \%$ en los animales vacunados con la esterasa recombinante, mientras que la vacuna de ADN pTARGET/ proteína esterasa cp09720 solo protegió al $16.6 \%$.

\section{Vacunas de subunidades proteicas recombinantes}

Las vacunas de subunidades combinan antígenos como lipopolisacáridos, proteínas recombinantes o péptidos sintéticos. Estas vacunas son muy seguras, pero poco inmunogénicas, por lo que se utilizan sustancias adyuvantes que potencien la respuesta del sistema inmune. La proteína PLD obtenida por vía recombinante ha sido de las más empleadas para el desarrollo de vacunas de subunidades. Un grupo de investigadores del Reino Unido determinó las potencialidades de una vacuna a partir de $50 \mu \mathrm{g}$ de PLD obtenida por vía recombinante (PLDr) en $E$. coli y su combinación con $1.25 \times 10^{10}$ células $/ \mathrm{ml}$ de cultivos totales de $C$. pseudotuberculosis inactivados con formalina. En este trabajo, el grupo control fue vacunado con la vacuna comercial Glanvac 3 (Commonwealth Serum Laboratories (CSL) Ltd., Victoria, Australia). Los niveles más altos de anticuerpos fueron detectados en los grupos inmunizados con la vacuna de PLDr y la vacuna PLDr + células totales inactivadas, en comparación con los grupos controles ${ }^{(73)}$.

La proteína PLDr junto a cultivos totales de C. pseudotuberculosis biovar ovis y equi, inactivados con formalina, fueron empleados para la inmunización de ovinos. La detección de los niveles de anticuerpos anti-PLD mediante ELISA permitió detectar que los animales vacunados presentaron un aumento de $\operatorname{IgG}$ después de la segunda dosis de refuerzo, pero luego del desafío se produjo una disminución en la DO de 0.65 a 0.55 , aunque los niveles se mantuvieron por encima del valor de corte durante 20 semanas. No se observaron lesiones en nódulos linfáticos externos e internos, en comparación con el grupo control no vacunado donde el $80 \%$ de los animales presentaron lesiones y manifestaciones de la enfermedad. Ambas vacunas fueron capaces de proteger a los animales ante el desafío con una cepa virulenta. En este trabajo por primera vez se inmunizan ovejas con una cepa biovar equi en combinación con la PLDr ${ }^{(87)}$.

Diferentes proteínas obtenidas por vía recombinante rCP09720 (esterasa), rCP01850 (proteína L14 de unión a la subunidad ARNr 50S) y la PLD (rPLD) también se han evaluado en la inmunización de ratones BALB/c. En este estudio, las tasas de supervivencia después del desafío con una cepa virulenta fueron de $30 \%$ (rPLD), 40\% (rPLD + rCP09720) y $50 \%$ $(\mathrm{rPLD}+\mathrm{rCP} 01850)$. La vacuna rPLD + rCP01850 fue capaz de inducir una respuesta inmune 
celular aumentando significativamente los niveles de IFN- $\gamma$ y TNF- $\alpha$, mientras que la producción de IL4 e IL12 no fue detectada ${ }^{(88)}$.

También se empleó una cepa viva atenuada de Mycobacterium bovis BCG (BacillusCalmette- Guerin) para la expresión de PLD recombinante en el plásmido pUS2000. El sistema no fue eficiente para la expresión elevada de la proteína PLD, pero fue efectivo para la vacunación y protección en un modelo murino. La inmunización de ratones $\mathrm{BALB} / \mathrm{c}$ con $10^{6}$ UFC de M. bovis pUS2000/PLD para la expresión de PLD, así como con M. bovis pUS2000/PLD+ 50 $\mu \mathrm{g}$ de PLDr purificada y la cepa $M$. bovis sin modificar, indujo una producción de anticuerpos elevada en comparación con el control negativo (100 $\mu \mathrm{l}$ de $\mathrm{Na} \mathrm{Cl}$ $0.9 \%$ ), pero sin diferencias significativas entre los grupos vacunados. Esto se debe a que la cepa $M$. bovis por si sola es capaz de inducir una respuesta inmune humoral y celular elevada. Sin embargo, ante el desafío con 2 x $10^{4}$ UFC de la cepa virulenta MIC-6, el grupo vacunado con $M$. bovis pUS2000/PLD experimentó un aumento significativo en los niveles de IgG en comparación con el resto de los grupos. La respuesta inmune celular se evaluó midiendo los niveles de producción de IFN- $\gamma$ e IL-10 en los sobrenadantes de cultivo de células de bazo de los animales vacunados, tras ser estimuladas con $8 \mu \mathrm{g} / \mathrm{ml}$ de PLDr. Los niveles de IFN- $\gamma$ e IL-10 fueron superiores en el cultivo celular del grupo que recibió una reactivación de la vacunación con $50 \mu \mathrm{g}$ de PLDr. El nivel de protección conferida por estas formulaciones fue del $88 \%$ en los animales vacunados con $M$ bovis pUS2000/PLD+ $50 \mu \mathrm{g}$ de PLDr, de $77 \%$ para el grupo M. bovis pUS2000/PLD y del $66 \%$ para el grupo $M$. bovis no modificado. La respuesta inmune protectora generada por esta vacuna de células enteras de $M$. bovis BCG modificada para expresar PLD, podría originar la activación de varias poblaciones de células $\mathrm{T}$, debido a la variedad de antígenos (lípidos, proteínas y carbohidratos) de la formulación. Luego la re-inmunización con $50 \mu \mathrm{g}$ de la PLD obtenida vía recombinante estimula el aumento en la proliferación de células T específicas para este antígeno en particular ${ }^{(89)}$.

Las vacunas de subunidades también se han desarrollado empleando la proteína CP40 obtenida por vía recombinante. La preparación de las vacunas de PLD a partir de sobrenadantes de cultivo de $C$. pseudotuberculosis habitualmente contienen otros antígenos, que podrían estar contribuyendo con la respuesta inmune protectora. La proteína CP40 fue identificada en preparaciones de vacunas inactivadas, a través de ensayos de inmunoblot, donde se observó que los sueros de animales vacunados con Glanvac 6 podían reconocer de manera intermitente esta proteína, lo que sugiere que estaba presente en algunos lotes de vacuna $^{(82)}$. En un estudio experimental en ovejas, la inmunización con $100 \mu \mathrm{g}$ de CP40 recombinante protegió al $82 \%$ de los animales, con una disminución de las lesiones pulmonares en un $98 \%$. No se encontró relación entre la disminución en el desarrollo de lesiones pulmonares y el titulo de anticuerpos, por lo que se asumió que la respuesta celular, como citotoxicidad celular dependiente de anticuerpos, podría ser responsable de la protección $^{(43)}$. 
Posteriormente se realizó la evaluación comparativa de cuatro formulaciones vacunales, que utilizaron como inmunógenos la proteína CP40 recombinante y la cepa CP09 atenuada mediante mutagénesis inducida. La cepa viva atenuada de $C$. pseudotuberculosis CP09 no fue capaz de inducir una respuesta inmune humoral en los ratones vacunados, ni desafiados con una cepa virulenta. Los animales vacunados con las formulaciones que incluían CP40r presentaron un aumento significativo en el título de anticuerpos IgG1. Sin embargo, estos grupos luego del desafío experimentaron un aumento significativo en los niveles de IgG2, siendo el máximo alcanzado por los animales inmunizados con CP40r. La formulación a base de CP40r protegió al $90 \%$ de los animales ante el desafío con la cepa virulenta, seguido del grupo vacunado con la cepa atenuada CP09 + CP40r con $70 \%$, mientras que la vacunación con CP40r seguido de la re-inmunización con CP09 solo protegió al $60 \%{ }^{(90)}$.

Otro grupo de investigadores realizó la evaluación en ratones BALB/c de una vacuna de subunidades de CP40r con diferentes adyuvantes, saponina o adyuvante completo de Freud (ACF). Los animales inmunizados con CP40r/saponina mostraron valores elevados en los niveles completos de anticuerpos y de IgG2a, IgG2b e IgG3, con diferencias estadísticas significativas con respecto al grupo control. El grupo vacunado con $\mathrm{CP} 40 \mathrm{r} / \mathrm{ACF}$ mostró diferencias significativas en los niveles completos de $\operatorname{IgG}$, IgG2a e IgG2b. Ambas formulaciones vacunales protegieron al $100 \%$ de los animales desafiados con $10^{4}$ UFC de $C$. pseudotuberculosis cepa virulenta C57, con una tendencia hacia una respuesta de Th1. La reactividad y la producción de isotipos específicos IgG2a, IgG2b e IgG3 se asocian con la acción de las citocinas pro-inflamatorias como IFN- $\gamma$ y las células T CD8+, que activan las células B modificando la cadena pesada de la inmunoglobulina. El uso de diferentes adyuvantes no influyó en la respuesta de anticuerpos, por lo que se propone el empleo de la saponina en sustitución del adyuvante de Freud que es tóxico en ovejas ${ }^{(91)}$.

\section{Conclusiones}

La linfadenitis caseosa continúa siendo un reto para los productores ovinos y caprinos a nivel mundial. Las investigaciones más recientes se han enfocado en la identificación de nuevas moléculas implicadas en los mecanismos de patogenicidad y virulencia de $C$. pseudotuberculosis, para su posterior evaluación como candidatos vacunales. Hasta la fecha se han obtenido resultados alentadores con formulaciones a base de la exotoxina PLD o la endoglicosidasa CP40, obtenidas por vía recombinante. Cabe destacar que la combinación de estas moléculas no se ha evaluado en una misma vacuna, lo cual sería una propuesta que favorecería la activación de la respuesta inmune humoral y celular. Por otra parte, la aplicación del análisis computacional en estudios de vacunología reversa constituye una de las herramientas más empleadas actualmente en la búsqueda de moléculas candidatas vacunales. Sin duda se debe continuar trabajando con el empleo de estas tecnologías que constituyen una alternativa eficiente para la identificación de nuevos factores de virulencia, 
así como la evaluación in silico de moléculas con potencial inmunogénico para el desarrollo de vacunas eficaces.

\section{Conflicto de intereses}

Los autores declaran que no existe conflicto de intereses.

\section{Literatura citada:}

1.Dorella FA, Pacheco LG, Oliveira SC, Miyoshi A, Azevedo V. Corynebacterium pseudotuberculosis: microbiology, biochemical properties, pathogenesis and molecular studies of virulence. Vet Res 2006;37(2):201-218.

2. Paton MW, Rose IR, Hart RA, Sutherland SS, Mercy AR, Ellis TM, et al. New infection with Corynebacterium pseudotuberculosis reduces wool production. Aust Vet J 1994; 71:47-49.

3. Collett MG, Bath GF, Cameron CM. Corynebacterium pseudotuberculosis infections. In: Coetzer J, Thomson GR, Justin RC, editores. Infectious diseases of livestock with special reference to Southern Africa. Cape Town, South Africa: Oxford University Press; 1994:1387-1395.

4. Schreuder BE, Ter Laak EA, De Gee AL. Corynebacterium pseudotuberculosis in milk of CL affected goats. Vet Rec 1990;127(15):387.

5.Faeza NMN, Jesse FFA, Hambal IU, Odhah MN, Umer M, Wessam MMS, et al. Responses of testosterone hormone concentration, semen quality, and its related pro-inflammatory cytokines in bucks following Corynebacterium pseudotuberculosis and its mycolic acid infection. Trop Anim Health Prod 2019;51(7):1855-1866.

6.Paton MW, Walker SB, Rose IR, Watt GF. Prevalence of Caseous lymphadenitis and usage of Caseous lymphadenitis vaccines in sheep flocks. Aust Vet J 2003;81:91-95.

7.Windsor PA. Control of Caseous Lymphadenitis. Vet Clin Food Anim 2011;27:193-202.

8.Williamson LH. Caseous lymphadenitis in small ruminants. Vet Clin North Am Food Anim Pract 2001;17(2): 359-371.

9.Aleman MR, Spier SJ. Corynebacterium pseudotuberculosis infections. In: Smith PB, editor. Large animal internal medicine, 3rd ed. St. Louis: Mosby Co. 2002:1076-1084.

10.Bastos BL, Dias PRW, Dorella FA, Ribeiro D, Seyffert N. Corynebacterium pseudotuberculosis: Immunological responses in animal models and zoonotic potential. J Clin Cell Immunol 2012;S4 (005):1-15. 
11.Gao H, Ma Y, Shao Q, Hong Q, Zheng G, Li Z. Genome sequence of Corynebacterium pseudotuberculosis strain KM01, isolated from the abscess of a goat in Kunming, China. Genome Announc 2018;6(11):e0013-18.

12.Windsor P. Managing control programs for ovine Caseous lymphadenitis and Paratuberculosis in Australia, and the need for persistent vaccination. Vet Med Auckl 2014;5:11-22.

13.de Farias AEM, Alves JRA, Alves FSF, Pinheiro RR, Faccioli MPY, Lima A MC, et al. Seroepidemiological characterization and risk factors associated with seroconversion to Corynebacterium pseudotuberculosis in goats from Northeastern Brazil. Trop Anim Health Pro 2019;51(4):745-752.

14.Debien E, Hélie P, Buczinski S, Leboeuf A, Bélanger D, Drolet R. Proportional mortality: A study of 152 goats submitted for necropsy from 13 goat herds in Quebec, with a special focus on Caseous lymphadenitis. Can Vet J 2013;54:581-587.

15. Varela GJA, Montes de Oca JR, Acosta JD, Hernández FL, Morales EV, Monroy SGH. First report of isolation and molecular characterization of the pathogenic Corynebacterium pseudotuberculosis from of sheep and goats in Mexico. Microb Pathog 2018;117:304-309.

16. Parise D, Parise M, Viana MVC, Muñoz BAV, Cortés-Pérez YA, Azevedo V et al. First genome sequencing and comparative analyses of Corynebacterium pseudotuberculosis strains from Mexico. Stand in Genomic Sci 2018;13(21).

17. Robins R. Focus on Caseous lymphadenitis. State Vet J 1991;1:7-10.

18. Binns SH, Bailey M, Green LE. Postal survey of ovine Caseous lymphadenitis in the United Kingdom between 1990 and 1999.Vet Record 2002;150(9):263-268.

19. Paton M, Rose I, Hart R, Sutherland S, Mercy A, Ellis T. Post-shearing management affects the seroincidence of Corynebacterium pseudotuberculosis infection in sheep flocks. Prev Vet Med 1996;26(3-4):275-284.

20.Santos LM, Stanisic D, Menezes UJ, Mendonça MA, Barral TD, Seyffert N, et al. Biogenic silver nanoparticles as a post-surgical treatment for Corynebacterium pseudotuberculosis infection in small ruminants. Front Microbiol 2019;10:824.

21.Stanisic D, Fregonesi NL, Barros CHN, Pontes JGM, Fulaz S, Menezes UJ, et al. NMR insights on nano silver post-surgical treatment of superficial Caseous lymphadenitis in small ruminants. RSC Advances 2018;71.

22. Baird G, Synge B, Dercksen D. Survey of Caseous lymphadenitis seroprevalence in British terminal sire sheep breeds. Vet Record 2004;154:505-506. 
23. Pinto AC, de Sa PHCG, Ramos RTJ, Barbosa S, Barbosa, HPM, Ribeiro AC, et al. Differential transcriptional profile of Corynebacterium pseudotuberculosis in response to abiotic stresses. BMC Genomics 2014;15:14.

24.Gallardo A, Toledo RA, González-Pasayo RA, Azevedo V, Robles C, Paolicchi FA, et al. Corynebacterium pseudotuberculosis biovar ovis evaluación de la sensibilidad antibiótica in vitro. Rev Argent Microbiol 2019;51(4):334-338.

25. Stefanska I, Gierynska M, Rzewuska M, Binek M. Survival of Corynebacterium pseudotuberculosis within macrophages and induction of phagocytes death. Polish J Vet Sci 2010;13(1):143-149.

26.OIE, Organización Mundial de Sanidad Animal. Informe del grupo ad hoc de la OIE sobre las enfermedades prioritarias para las cuales las vacunas pueden reducir el uso de agentes antimicrobianos en bovinos, ovejas y cabras. Paris, 2018. http//:www.oie.int > fileadmin > SST > adhocreports > AHG.

27. de Pinho RB, de Oliveira Silva MT, Bezerra FSB. Vaccines for caseous lymphadenitis: up-to-date and forward-looking strategies. Appl Microbiol Biotechnol 2021;105:22872296.

28. Wattam ARJ, Davis J, Assaf R, Brettin T, Bun C, Conrad N, et al. Improvements to PATRIC, the all-bacterial bioinformatics database and analysis resource. Nucleic Acids Res 2017;45:535-542.

29. Ruiz JC, D’Afonseca V, Silva A, Ali A, Pinto AC. Evidence for reductive genome evolution and lateral acquisition of virulence functions in two Corynebacterium pseudotuberculosis strains. PLoS One 2011;6(4):e18551.

30. Burkovski A. The role of corynomycolic acids in Corynebacterium-host interaction. Antonie van Leeuwenhoek 2018;111(5):717-725.

31.Burkovski A. Cell Envelope of Corynebacteria: Structure and Influence on Pathogenicity. ISRN Microbiol 2013;935736:11.

32. Muller B, de Klerk LLM, Henton MM, Lane E, Parsons S, Kotze A, et al. Mixed infections of Corynebacterium pseudotuberculosis and non-tuberculous mycobacteria in South African antelopes presenting with tuberculosis-like lesions. Vet Microbiol $2011 ; 147: 340-345$.

33. Silva A, Schneider MPC, Cerdeira L, Barbosa MS, Ramos RTJ. Complete genome sequence of Corynebacterium pseudotuberculosis I19, a strain isolated from a cow in Israel with bovine mastitis. J Bacteriol 2011;193:323-324. 
34. Sprake P, Gold JR. Corynebacterium pseudotuberculosis liver abscess in a mature alpaca (Lama pacos). Can Vet J 2012;53:387-390.

35. Lopes T, Silva A, Thiago R, Carneiro A, Dorella FA. Complete genome sequence of Corynebacterium pseudotuberculosis Strain Cp267, isolated from a Llama. J Bacteriol 2012;194:3567-3568.

36. Colom CA, Velarde R, Salinas J, Borge C, Garca BI, Serrano E, et al. Management of a Caseous lymphadenitis outbreak in a new Iberian ibex (Capra pyrenaica) stock reservoir. Acta Vet Scand 2014;56:83.

37.Oliveira M, Barroco C, Mottola C, Santos R, Lemsaddek A, Tavares L, Semedo LT. First report of Corynebacterium pseudotuberculosis from Caseous lymphadenitis lesions in Black Alentejano pig (Sus scrofa domesticus). Vet Res 2014;10:218.

38. Muñoz BAV, Cortés PYA, Arellano RB, Hernández GM, Hernández CR, Díaz AE. Identification of Corynebacterium pseudotuberculosis isolated from muscular abscesses in two horses: first report in Mexico. Equine Vet Educ 2016;29(8):431-435.

39. Borham M, Oreiby A, El GA, Al GM. Caseous Lymphadenitis in Sudanese and Somalian camels imported for meat consumption in Egypt. AJVS 2017;55(2):52-59.

40. Viana MVC, Figueiredo H, Ramos R, Guimares LC, Dorella FA, Azevedo V. Comparative genomic analysis between Corynebacterium pseudotuberculosis strains isolated from buffalo. PLoS ONE 2017;12(4):e0176347.

41. Soares SC, Silva A, Trost E, Blom J, Ramos R, Carneiro A. The pan-genome of the animal pathogen Corynebacterium pseudotuberculosis reveals differences in genome plasticity between the biovar ovis and equi strains. PLoS ONE 2013;8(1):e53818.

42. Odhah MN, Jesse FFA, Lawan A, Idris UH, Marza AD, Mahmood ZK, et al. Responses of haptoglobin and serum amyloid $\mathrm{A}$ in goats inoculated intradermally with $C$. pseudotuberculosis and mycolic acid extract immunogen. Microb Pathog 2018;117:243246.

43. Hodgson ALM, Bird P, Nisbett IT. Cloning, nucleotide sequence, and expression in Escherichia coli of the phospholipase D gene from Corynebacterium pseudotuberculosis. J Bacteriol 1990;172:1256-1261.

44. Kolesnikov YS, Nokhrina KP, Kretynin SV, Volotovski ID, Martinec J, et al. Molecular structure of phospholipase D and regulatory mechanisms of its activity in plant and animal cells. Biochem Biokhimiia 2012;77:1-14. 
45. Dias-Lopes C, Neshich IAP, Neshich G, Ortega JM, Granier C, Chávez-Olortegui C, et al. Identification of new Sphingomyelinases D in pathogenic fungi and other pathogenic organisms. PLoS ONE 2013;8(11):e79240.

46. Baird GJ, Fontaine MC. Corynebacterium pseudotuberculosis and its role in ovine Caseous Lymphadenitis. J Comp Pathol 2007;137(4):179-210.

47. Walker J, Wilson MJ, Brandon MR. Molecular and biochemical characterization of a protective 40-kilodalton antigen from Corynebacterium pseudotuberculosis. Infect Immun 1995;63:206-211.

48. Shadnezhad A, Naegeli A, Collin M. CP40 from Corynebacterium pseudotuberculosis is a endo B-N- acetylglucosaminidase. BMC Microbiol 2016;63(1):206-211.

49. Pacheco LGC, Slade SE, Seyffert N, Santos AR, Castro TLP. A combined approach for comparative exoproteome analysis of Corynebacterium pseudotuberculosis. BMC Microbiol 2011;11:12.

50. Paule BJ, Meyer R, Moura-Costa LF, Bahia RC, Carminati R, Regis LF. Three-phase partitioning as an efficient method for extraction / concentration of immunoreactive excreted-secreted proteins of Corynebacterium pseudotuberculosis. Protein Expr Purif 2004;34:311-316.

51. Silva WM, Dorella FA, Soares SC, Souza GHM, Seyffert N, Azevedo V, et al. A shift in the virulence potential of Corynebacterium pseudotuberculosis biovar ovis after passage in a murine host demonstrated through comparative proteomics. BMC Microbiol 2017;17(1):55.

52. Corrêa JI, Stocker A, Castro ST, Vale V, Brito T, Bastos B, et al. In vivo and in vitro expression of five genes involved in Corynebacterium pseudotuberculosis virulence. AMB Expr 2018;8:89.

53. Ibraim IC, Parise MT, Tadra MZ, de Paula TL, Wattam AR, Azevedo V, et al. Transcriptome profile of Corynebacterium pseudotuberculosis in response to iron limitation. BMC Genomics 2019;20:663.

54. Ibraim IC, Parise MT, Tadra MZ, de Paula TL, Wattam AR, Azevedo V, et al. Transcriptome profile of Corynebacterium pseudotuberculosis in response to iron limitation. BMC Genomics 2019;20:663.

55. Sa1d-Salim B, Mostowy S, Kristof AS, Behr MA. Mutations in Mycobacterium tuberculosis RV0444c, the gene encoding anti-sigK, explain high level expression of mpb70 and mpb83 in Mycobacterium bovis. Mol Microbiol 2006;62:1251-1263. 
56. Pacheco LGC, Castro TLP, Carvalho RD, Moraes PM, Dorella FA, Azevedo V, et al. A role for sigma factor $\sigma$ in Corynebacterium pseudotuberculosis resistance to nitric oxide/peroxid stress. Front Microbiol 2012;3:126.

57. Trost E, Ott L, Schneider J, Schröder J, Jaenicke S, Goesmann A, Husemann P, et al. The complete genome sequence of Corynebacterium pseudotuberculosis FRC41 isolated from a 12-year-old girl with necrotizing lymphadenitis reveals insights into gene regulatory networks contributing to virulence. BMC Genomics 2010;11:728.

58. Costa PM, McCulloch JA, Almeida SS, Dorella FA, Fonseca CT, et al. Molecular characterization of the Corynebacterium pseudotuberculosis hsp60-hsp10 operon, and evaluation of the immune response and protective efficacy induced by hsp60 DNA vaccination in mice. BMC Res Notes 2011;4:243.

59. Pinto GAC, Gomes SP, Queiroz AL, Sousa T, Rodrigues L, Azevedo V, et al. Heat shock stress: Profile of differential expression in Corynebacterium pseudotuberculosis biovar Equi Gene 2018;645:124-130.

60. Silva WM, Seyffert SN, Santos AV, Castro TLP, Pacheco LGC, Azevedo V, et al. Identification of 11 new exoproteins in Corynebacterium pseudotuberculosis by comparative analysis of the exoproteoma. Microb Pathog 2013;1e6:1-6.

61. Al-Gaabary MH, Osman SA, Oreiby AF. Caseous lymphadenitis in sheep and goats: Clinical, epidemiological and preventive studies. Small Ruminant Res 2009;87:116121.

62. Jesse FFA, Odhah MN, Abbad Y, Garba B, Mahmood Z, Hambali IU, et al. Responses of female reproductive hormones and histopathology in the reproductive organs and associated lymph nodes of Boer does challenged with Corynebacterium pseudotuberculosis and its immunogenic corynomycolic acid Extract. Microb Pathog 2020;139:103852.

63. Odhah MN, Jesse FFA, Teik CEL, Mahmood Z, Wahid HA, Mohd LMA, et al. Clinicopathological responses and PCR detection of Corynebacterium pseudotuberculosis and its immunogenic mycolic acid extract in the vital organs of goats. Microb Pathog 2019;135:103628.

64.Mahmood ZKH, Jesse FF, Saharee AA, Jasni S, Yusoff R, Wahid H. Clinio-pathological changes in goats challenged with Corynebacterium peudotuberculosis and its exotoxin (PLD). Am J Anim Vet Sci 2015;10 (3):112.132.

65.Valdivia J. Vida intracelular de Corynebacterium pseudotuberculosis [tesis Doctorado]. España, Islas Canarias: Universidad de las Palmas de Gran Canaria. Instituto Universitario de Sanidad animal y Seguridad alimentaria; 2015. 
66. Oliveira A, Oliveira LC, Aburjaile F, Benevides L, Tiwari S, Azevedo V, et al. Insight of Genus Corynebacterium: Ascertaining the role of pathogenic and non-pathogenic species. Front Microbiol 2017;8:1937.

67. Oliveira A, Teixeira P, Barh D, Barh D, Ghosh P, Azevedo V. Key amino acids in understanding evolutionary characterization of $\mathrm{Mn} / \mathrm{Fe}-\mathrm{Superoxide}$ dismutase: A phylogenetic and structural analysis of proteins from Corynebacterium and Hosts. Trends Artif Intell 2017;1(1):1-11.

68. Hard GC. Examination by electron microscopy of interaction between peritoneal phagocytes and Corynebacterium ovis. J Med Microbiol 1972;5:483-491.

69. Tashjian JJ, Campbell SG. Interaction between caprine macrophages and Corynebacterium pseudotuberculosis: an electron microscopy study. Am J Vet Res 1983;44:690-693.

70. Paule BJA, Azevedo V, Regis LF, Carminati R, Bahia R. Experimental Corynebacterium pseudotuberculosis primary infection in goats: kinetics of $\operatorname{IgG}$ and interferon- $\gamma$ production, IgG avidity and antigen recognition by Western blotting. Vet Immunol Immunopathol 2003;96:129-139.

71. Seyffert N, Silva RF, Jardin J, Silva WM, Castro TL, Tartaglia NR, et al. Serological proteome analysis of Corynebacterium pseudotuberculosis isolated from different hosts reveals novel candidates for prophylactics to control Caseous lymphadenitis. Vet Microbiol 2014;174:255-260.

72. Rebouças MF, Portela RW, Lima DD, Loureiro D, Bastos BL. Corynebacterium pseudotuberculosis secreted antigen-induced specific gamma-interferon production by peripheral blood leukocytes: Potential diagnostic marker for Caseous Lymphadenitis in sheep and goats. J Vet Diag Invest 2011;23:213-220.

73. Fontaine MC, Baird G, Connor KM, Rudge K, Sales J, Donachie, W. Vaccination confers significant protection of sheep against infection with a virulent United Kingdom strain of Corynebacterium pseudotuberculosis. Vaccine 2006;24:5986-5996.

74. Stanford K, Brogden KA, McClelland LA, Kozub GC, Audibert F. The incidence of Caseous lymphadenitis in Alberta sheep and assessment of impact by vaccination with commercial and experimental vaccines. Can J Vet Res 1998;62:38-43.

75. Zoetis, 2020. Zoetis Spain, S.L. Avda. de Europa 20B, Parque Empresarial La Moral. https://www.zoetis.es/_locale-assets/spc/biodectin.pdf. Consultado 16 Abr, 2020. 
76. Medrano G, Hung ACh, Alvarado AS, Li EO. Evaluación de una vacuna contra Corynebacterium pseudotuberculosis en ratones albinos. Rev Inv Vet 2003;14(1):6167.

77. Braga WU. Protection in alpacas against Corynebacterium pseudotuberculosis using different bacterial components. Vet Microbiol 2007;119:297-303.

78. Eggleton DG, Doidge CV, Middleton HD, Minty DW. Immunisation against ovine caseous lymphadenitis: efficacy of monocomponent Corynebacterium pseudotuberculosis toxoid vaccine and combined clostridial-corynebacterial vaccines. Aust Vet J 1991;68:320421.

79. Syame SM, Abuelnaga ASM, Ibrahim ES, Hakim AS. Evaluation of specific and nonspecific immune response of four vaccines for caseous lymphadenitis in sheep challenged. Vet World 2018;11(9):1272-1276.

80. Moura-Costa LF, Bahia RC, Carminati R, Vale VL, Paule BJ, et al. Evaluation of the humoral and cellular immune response to different antigens of Corynebacterium pseudotuberculosis in Canindé goats and their potential protection against Caseous lymphadenitis. Vet Immunol Immunopathol 2008;126:131-141.

81. Hodgson ALM, Krywult J, Corner LA, Rothel JS, Radford AJ. Rational attenuation of Corynebacterium pseudotuberculosis: Potential cheesy gland vaccine and live delivery vehicle. Infect Immun 1992;60(7):2900-2905.

82. Hodgson ALM, Tachedjian M, Corner LA, Radford AJ. Protection of sheep against Caseous lymphadenitis by use of a single oral dose of live recombinant Corynebacterium pseudotuberculosis. Infect and Immunol 1994;62(12):5275-5280.

83. Ribeiro D, Rocha FS, Leite KM, Soares SC, Silva A, Portela RW, et al. An ironacquisition-deficient mutant of Corynebacterium pseudotuberculosis efficiently protects mice against challenge. Vet Res 2014;45:28.

84. Chaplin PJ, De Rose R, Boyle JS, McWaters P, Kelly J, Tennent JM, et al. Targeting improves the efficacy of a DNA vaccine against Corynebacterium pseudotuberculosis in sheep. Infect Immun 1999;67:6434-6438.

85. De Rose R, Tennent J, McWaters P, Chaplin PJ, Wood PR, Kimpton W, et al. Efficacy of DNA vaccination by different routes of immunisation in sheep, Vet Immunol Immunopathol 2002;90:55-63. 
86. Brum AA, Silva AFR, Silvestre FB, Collares T, Begnine K, Kommling F, et al. Recombinant esterase from Corynebacterium pseudotuberculosis in DNA and subunit recombinant vaccines partially protects mice against challenge. J Med Microb 2017;66:635-642.

87. Moussa IM, Mohamed SA, Ashgan M, Hessain SA, Kabli E, Hassan AH, et al. Vaccination against Corynebacterium pseudotuberculosis infections controlling Caseous lymphadenitis (CLA) and oedematousskin disease. Saudi J Biol Sci 2016;23:718-723.

88.Silva MTO, Bezerra FSB, de Pinho RB, Begnini KR, Seixas FK, Collares T, et al. Association of Corynebacterium pseudotuberculosis recombinant proteins rCP09720 or rCP01850 with rPLD as immunogens in Caseous lymphadenitis immunoprophylaxis. Vaccine 2018;36(1):74-83.

89. Leal KS, Silva TO, Silva AFR, Brilhante FSB, Begnini K, Seixas F, et al. Recombinant M. bovis BCG expressing the PLD protein promotes survival in mice challenged with a C. pseudotuberculosis virulent strain. Vaccine 2018;36:3578-3583.

90. Silva JW, Droppa-Almeida D, Borsuk S, Azevedo V, Portela RW. Corynebacterium pseudotuberculosis cp09 mutant and cp40 recombinant protein partially protect mice against caseous lymphadenitis. BMC Vet Res 2014;10:965.

91. Droppa-Almeida D, Vivas WL, Silva KK, Rezende AF, Simionatto S. Recombinant CP40 from Corynebacterium pseudotuberculosis confers protection in mice after challenge with a virulent strain. Vaccine 2016;34(8):1091-1096. 